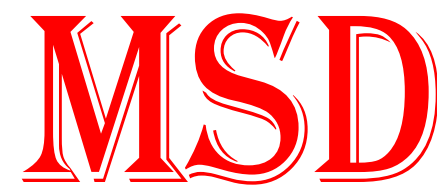

Medical Science and Discovery ISSN: 2148-6832

\title{
A study on substance abuse among young people (10- 24 years) in urban slums of Jorhat, Assam
}

\author{
Arya Nair Kovilveettil ${ }^{1} *$ \\ 1 Assam Medical Council, Assam, Jorhat, India \\ * Corresponding Author: Arya Nair Kovilveettil E-mail: ank.2907@ gmail.com
}

\section{ABSTRACT}

Objective: To find out the substances abused by the people in urban slums and also find factors contributing to it. Also to recommend suggestions based on the study

Material and Methods: It was a community based cross sectional study and data was collected using Interviewers Performa after getting approved by the Institutional Ethics Committee. A sample size of 174 was calculated. Young People (10 to 24yrs) who were willing to participate were included and whose not ready to take part were opted out.

Results: It was found that males usually 22 to 24yrs used abusive substances than females. Tobacco was the most common substance abused followed by alcohol and majority had been introduced to the substances by their peers between 17 to $24 \mathrm{yrs}$. Most people consumed the drug multiple times daily followed by weekly and had procured the drug from local retailers. These substances gave them a sense of hallucination and euphoria on consumption. Among the side effects oral problems like ulcers and malignancy topped the list. Respiratory and gastrointestinal issues along with inability to concentrate on work were other side effects.

Conclusions: Based on the results several recommendations were made especially awareness workshops and camps. These programs mainly stressed upon the necessity to create social awareness among the people and their families about the ill effects of substance abuse. All the results were tabulated.

Keywords: substance abuse, Tobacco, alcohol, young people, adolescents, slums, Jorhat,

\section{INTRODUCTION}

Every civilization known to us has provided for the use of mind-altering substances. There are medicinal, recreational, religious and social uses for these substances. Each culture develops its own set of parameters norms and practices in order to control the use of these substances and to contain the extent of their abuse. Substance abuse refers to the harmful or hazardous use of psychoactive substances, including alcohol and illicit drugs (1).

It is disturbing to know that, substance abuse has reached an alarming proportion in the recent years particularly among the young population (aged between 10-24 years) (2) as the habit of substance abuse is fast making inroads into their lives (3). The reason of fast growing abuse may be attributed to curiosity and natural tendency to experiment with drugs, disturbed home environment, lack of communication between parents and children, ignorance and its ill after effects, lack of knowledge, early exposure etc. Other important reasons contributing to it may be as a result of escape phenomena from tension and frustrations like unemployment, failure in exams, impact of 'disco culture', electronic media, peer pressure or delinquency.

According to ICD-10 (International Classification of Diseases), a medical classification list by WHO recognizes psychoactive substances as those, the self-administration of which produces mental and behavioural disorders (4). This may lead to abuse and subsequently addiction and dependence. The list includes alcohol, opioids, cannabinoids, sedatives and hypnotics, cocaine, caffeine and other stimulating agents, hallucinogens, tobacco and other volatile substances.

The situation of substance abuse among young people is becoming a global health problem and has reached an alarming position in India. 
Research on the abuse of substances has grabbed undivided attention in developing countries like India because of changing trends in the prevalence of substance abuse and the rising magnitude of the menace. Statistically speaking, 2 billion worldwide populations consume alcoholic beverages as documented by WHO, out of which 76.3 million have disorders having suicidal tendencies. Other psychological changes include mood disorders like anxiety, depression, thought disorders, and personality disorders. Tobacco causes more death than all psychoactive substances combined,including 3 million premature deaths ( $6 \%$ of total) and $30 \%$ of all cancer deaths (5). Considering our area of study, the socio-cultural, economic, as well as geographical factors has proved to be very conducive for the emergence of drug addiction and alcoholism in this region. The region is close to the 'Golden Triangle', and a major hub of drug transport and the second-largest opium producer, provides an ample push in worsening the scenario. Opium, ganja, bhang, alcohol, khaini, bidi etc. are the most commonly abused substances. Coming back to Indian scenario, the Childline foundation survey in 2008 revealed $63 \%$ of patients coming with substance abuse-related disorders were introduced to it in their young age between 10 to 24 years. The cases of drug abuse are fast rising to $12 \%$ in age group upto 15 years and $32 \%$ in 16-25 years age group (6).

A thorough review of the published papers on this topic can define the causative factors and help to assess planning and suggest further studies in this domain.

In our project, the extent, pattern and trend of drug abuse amongst the young people aged between 10 to 24 years of Jorhat Slum, viz. Pujadubi and .Dhakaipatty.Before commencing the study approval was taken from Institutional Ethics Committee of Jorhat Medical College and Hospital

\section{MATERIAL and METHODS}

Young People: The age of young people are taken to be between 10 to 24 years (2).

Substance abuse: In our study the substances considered were Alcohol, Cigarette, Tobacco products, Dendrite and Marijuana (Bhang).

Abuse: A substance was considered to be abused if it was used in an amount harmful to his/her health, either mentally or physically or both.

Scope of study: People of all age groups are seen to be suffering from the harmful effects of substance abuse. The age group included in our project, i.e., between 10 years to 24 years of age, is the major age group involved in such practices, commonly resulting in many physical, mental and social disturbances (7).

Data obtained from our research can be used to conduct educational programmes on substance abuse. We can provide the people information on how to deal with a family member or friend who is struggling with a substance use disorder, make them aware of the probable side effects and also advice them to avoid the use of such substances.

Limitations: Being undergraduates, with minimum resources and limited time, we could not afford a more extensive intervention into the matter. We could only provide our study subjects with on the spot advices and information regarding substance abuse and its effects.

\section{Objectives}

1. To find out the substances abused and the factors contributing to it.

2. To suggest recommendations based on our study.

Literature review: According to the study named "Substance abuse among Youths at Guwahati city, ASSAM (India)major instigators and socio demographic factors" by Himakshi Goswami conducted at Guwahati among 100 substance abused youth, the pattern reveals that $49 \%$ of the respondents use alcohol, $22 \%$ use heroin, $2 \%$ marijuana, $3 \%$ ganja, $2 \%$ inhalers, $19 \%$ polydrug and $3 \%$ cocaine. The pattern for the major instigators of substance abuse revealed that $29 \%$ used it for fun, $25 \%$ by peer influence, $23 \%$ reported that their curiosity for the drug acted as propagates and $9 \%$ used it to get relief from stress (8).

Research conducted on the extent and patterns of drug abuse by general population surveys in India showed that the prevalence of alcohol abuse varied between 4.2 and $30.7 \%$, heroin abuse between 0 and $1.3 \%$, and other opiates between 0 and $10.2 \%$ in the country. Heroin abuse was frequently reported from Manipur and Kohima and was around 1\%, raw opium abuse from Jodhpur and that of cannabis from Uttar Pradesh and Manipur (9).

According to the study "Developing Community Drug Rehabilitation, Rapid Assessment Study of Drug Abuse in Target Communities in India (RAS DATC)" by Mittal and Ch'ien, conducted in nine urban cities namely Bangalore, Chennai, Imphal, Jodhpur, Kolkata, Lucknow, Mumbai, Patna and Pune, it was reported that among a total of 1,271 drug users , commonly used drugs in descending order were: alcohol $43 \%$, heroin $38.2 \%$, opium $9.3 \%$, cannabis $6.1 \%$ and other opiates $4.3 \%$ (10).

The National Household Survey of Drug Use in the country reported that alcohol was the primary substance used (apart from tobacco) followed by cannabis $3 \%$ and opioids $0.7 \%$ (11).

According to United Nations office on drug and crime, the states of India bordering Myanmar have experienced very rapid transmission of HIV among drug injecting populations. Zero prevalence among intravenous drug users increased from $0 \%$ to $50 \%$ within six months in 1989 , injecting drug use for non medical purpose increased rapidly during the last decades and was a major contributing factor for various infective diseases like HIV in young generation (12).

In Manipur, Mizoram and Nagaland the anonymous surveys shows that the prevalence of intravenous drug users varies between 1 and $2 \%$ of the general population in the states concerned. Thus Manipur accommodates for at least 15,000 intravenous drug users in the entire state, Nagaland 1,500 and Mizoram 2,800 in surveyed urban areas. The intravenous injections are $0.2 \%$ in remote areas, $0.9 \%$ in areas far away from the highway and $1.3 \%$ in areas that are well connected with the highway. Heroin users are much higher in these areas (13). 
According to the study, "Substance use among adolescent high school students in India: a survey of knowledge, attitude and opinion" conducted in two high schools in West Bengal, India, among 416 students in classes 8, 9 and 10, the results show that $52(12.5 \%)$ used or abused any of the substance. 26 out of 172 were urban and the others 26 out of 244 were rural students. $73 \%$ of respondents expressed their desire to quit and $57.69 \%$ had tried to stop (12)

\section{Study design and participants}

In our project, a community based cross sectional study was carried out in urban slums of Jorhat (Pujadubi and Dhakaipatty) under the guidance of the Department of Community Medicine, Jorhat Medical College and Hospital, Jorhat. The study sample was selected from among young people (aged between 10 to 24 years of age) to study the substance abused along with the factors responsible for it. The project was completed within a period of four months from MAY to SEPTEMBER, 2017.

\section{Preparatory phase: MAY - JUNE}

\section{Data collection: JULY - AUGUST}

\section{Report writing: AUGUST - SEPTEMBER}

This age group was selected because substance abuse practices were found to be most common among this age group due to various reasons like peer pressure, familial pressure, stress, urge to experimentation, etc.

\section{Sample size:}

Based on all the details mentioned above the sample size was calculated using the equation (13).

$\mathrm{n}=4 \mathrm{pq} / \mathrm{L} 2(15)$

Where: $\mathrm{p}$ is prevalence

$\mathrm{q}$ is non prevalence $\{1-\mathrm{p}\}$

$\mathrm{L}$ is the absolute error

\section{RESULTS}

Table 1: Gender distribution of substance abuse

\begin{tabular}{|lcc|}
\hline Gender & Total number & In percentage \\
\hline Male & 153 & 87.99 \\
\hline Female & 21 & 12.21 \\
\hline Total & 174 & 100 \\
\hline
\end{tabular}

Table 2: Prevalence according to age

\begin{tabular}{|lcc|}
\hline Age Group (In Years) & Total Number & In Percentage \\
\hline $10-13$ & 1 & 0.6 \\
$13-16$ & 13 & 7.5 \\
$16-19$ & 36 & 20.7 \\
$19-22$ & 59 & 33.9 \\
$22-24$ & 63 & 36.2 \\
\hline TOTAL & 174 & 100 \\
\hline
\end{tabular}

Taking, $\mathrm{p}=12.5 \%$

$$
\begin{aligned}
& \mathrm{L}=10 \% \\
& \mathrm{~N}=174
\end{aligned}
$$

And substituting in the above equation, we get 174 as the sample size.

\section{Inclusion criteria:}

All those abusing one substance or the other in the age group of 10 to 24 years.

Those who were willing to participate.

Those using multiple substance of abuse were also included

\section{Exclusion criteria:}

Those who did not report any instance of substance abuse till the date of survey.

Those who were not willing to participate.

Those aged below 10 years and above 24 years.

\section{Study area and population}

The study was conducted in the urban slums of Pujadubi and Dhakaipatty of Jorhat. It has a population mainly of daily wage workers and their families.

Simple random sampling technique was used for conducting our study. The slums were randomly selected from among the registered slums under Jorhat Development Authority. House to house visit was done in the two slums till 174 young people who reported of substance were reached.

Data collection tools: Informed consent was taken from the participants. They were assured of the confidentiality of the information given. Data was collected by using a predesigned and pre-tested Performa by the INTERVIEW METHOD. 
Table 3: Types of drugs abused in percentage

\begin{tabular}{|lcc|}
\hline Drugs abused & Total number & In percentage \\
\hline Dendrite & 11 & 6.32 \\
Marijuana and derivatives & 8 & 4.60 \\
Alcohol & 47 & 27.01 \\
Tobacco and derivatives & 92 & 52.87 \\
Marijuana+Alcohol+Tobacco and derivatives & 8 & 4.6 \\
\hline Alcohol+Tobacco and derivatives & 8 & 4.6 \\
\hline Total & 174 & 100 \\
\hline
\end{tabular}

Table 4: Frequency of drug intake:

\begin{tabular}{lcc} 
Frequency & Total number & In percentage \\
\hline Daily once & 18 & 10.34 \\
Daily multiple & 110 & 63.21 \\
Weekly & 38 & 21.84 \\
Monthly & 8 & 04.61 \\
\hline Total & 174 & 100 \\
\hline
\end{tabular}

Table 5. Source of drug

\begin{tabular}{|lcc|}
\hline Source & Total number & In percentage \\
\hline Nearby retailer & 112 & 64.36 \\
\hline Drug handler(outside persons) & 9 & 5.17 \\
Friend & 11 & 6.32 \\
Family & 1 & 0.57 \\
Retailer +friend & 28 & 16.1 \\
Retailer +drug handler & 2 & 1.15 \\
Retailer+family & 11 & 6.32 \\
Total & 174 & 100
\end{tabular}

Table 6. Age at which first introduced:

\begin{tabular}{lcc} 
Age & Total number & In percentage \\
\hline $10-16$ & 60 & 34.48 \\
$17-24$ & 114 & 65.52 \\
Total & 174 & 100 \\
\hline
\end{tabular}

Table 7. The Mental state of the consumer after substance intake

\begin{tabular}{lcc} 
Feelings/effect & Total number & In percentage \\
\hline Euphoric & 26 & 14.94 \\
Hallucination & 13 & 7.47 \\
Relaxed & 45 & 25.86 \\
Depressed & 3 & 1.72 \\
Addictiveness & 17 & 9.77 \\
Euphoric+relaxed+addictiveness & 23 & 13.21 \\
Relaxed+depressed & 4 & 2.29 \\
Euphoric+hallucination+addictiveness & 43 & 24.71 \\
\hline Total & 174 & 100 \\
\hline
\end{tabular}

Table 8. The health effects of substance use on consumer's work

\begin{tabular}{lcc}
\hline Effect & Total number & In percentage \\
\hline Respiratory & 26 & 14.94 \\
G.i & 20 & 11.49 \\
Oral & 38 & 21.83 \\
Cns & 6 & 3.44 \\
\hline Unable to concentrate +loss of work efficacy & 34 & 19.54 \\
Unable to concentrate +absence from work & 20 & 11.49 \\
\hline Loss of work efficacy & 21 & 11.5 \\
No health effects seen & 9 & 5.17 \\
\hline Total & 174 & 100 \\
\hline
\end{tabular}


Table 8. The health effects of substance use on consumer's work:

\begin{tabular}{|lcc|}
\hline Effect & Total number & In percentage \\
\hline Respiratory & 26 & 14.94 \\
G.i & 20 & 11.49 \\
\hline Oral & 38 & 21.83 \\
Cns & 6 & 3.44 \\
\hline Unable to concentrate +loss of work efficacy & 34 & 19.54 \\
\hline Unable to concentrate +absence from work & 20 & 11.49 \\
\hline Loss of work efficacy & 21 & 11.5 \\
\hline No health effects seen & 9 & 5.17 \\
\hline Total & 174 & 100 \\
\hline
\end{tabular}

Table 9. Reasons for taking drugs:

\begin{tabular}{lcc} 
Reasons & Total number & In percentage \\
\hline Depression & 16 & 9.19 \\
Stress & 14 & 8.04 \\
Personal loss & 9 & 5.17 \\
Peer pressure & 83 & 47.70 \\
Experimentation & 33 & 18.96 \\
Experimentation + peer pressure & 6 & 3.44 \\
Stress + personal loss & 1 & 0.57 \\
Total & 174 & 100 \\
\hline
\end{tabular}

Table 10. Household factors contributing to drug abuse:

\begin{tabular}{|lcc|}
\hline Household scenario & Total number & In percentage \\
\hline Parental violence & 33 & 18.96 \\
\hline Lower socioeconomic condition & 44 & 25.28 \\
\hline Lack of guidance & 40 & 22.98 \\
Lack of bonding & 28 & 16.09 \\
Abused /battered & 13 & 7.47 \\
Neglected & 16 & 9.19 \\
\hline Total & 174 & 100 \\
\hline
\end{tabular}

Table 11. Family history of drug abuse

\begin{tabular}{lcc|}
\hline Family history & Total number & Percentage \\
\hline Present & 76 & 43.68 \\
Not present & 98 & 56.32 \\
\hline
\end{tabular}

Table 12. Family approach towards the drug abuser:

\begin{tabular}{lcc}
\hline Attitude and measures & Total number & Percentage \\
\hline Unaware & 88 & 50.57 \\
Aware but indifferent & 50 & 28.73 \\
Aware and advised & 36 & 20.68 \\
\hline
\end{tabular}

Table 13. Awareness of ill effects

\begin{tabular}{lcc} 
Status & Total number & In percentage \\
\hline Aware & 126 & 72.41 \\
Not aware & 48 & 27.59 \\
Total & 174 & 100 \\
\hline
\end{tabular}

\section{DISCUSSION}

What we have observed at the end of this study is quite remarkable. We have come to a conclusive fact that a very large proportion of the young age group is abusing one kind of drug or another.
We found that $87.99 \%$ of males and $12.21 \%$ females (Table1) were abusing one kind of drug or another in our study while in another study entitled "Drug abuse in slum population" conducted in 2014 in Indore Madhya Pradesh(India) by the department of psychiatry MGM 
Medical College Indore $78.2 \%$ were males and $28.2 \%$ were females. Thus indicating that males have a higher tendency towards vehement consumption of drugs (14).

The majority of drug abusers i.e. $36.2 \%$ belonged to age group $22-24$ followed by $33.9 \%$ in the age group 0f $19-21 \%$ (Table 2). However, in the study "Prevalence, pattern and familial effects of substance use among the male college students - North Indian Study" by Sorab Gupta the majority i.e. $60 \%$ belonged to the age group 19-21 followed by $39.4 \%$ in the age group 22-25. Though statistics may vary somewhat in both studies it is seen that young people in the age group 19-25 are most vulnerable (15).

The major drugs abused are tobacco (52.87\%) and alcohol (27.01\%). The study "Age of substance use initiation among treatment admissions aged 18-30" by Substance Abuse and Mental Health Services Administration (SAMHSA) U.S.A. also revealed that the majorly abused drugs were tobacco $(53.8 \%)$ and alcohol (19.7\%) (18).

$73.55 \%$ individuals take drugs daily and $21.84 \%$ weekly.However the study by Sorab Gupta reveals $49 \%$ take drugs daily and $23.8 \%$ weekly (18)

The most common source of drug were nearby retailers $(64.36 \%)$. Also friends in $6.32 \%$ cases, drug handlers in $5.17 \%$ cases and $23.57 \%$ got their drugs from more than 1 source.

The most common reason as concluded was peer pressure $(47.5 \%)$ by our study. Experimentation stood next at $18.96 \%$. The study"Factors influencing alcohol and tobacco addiction among patients attending de addiction centre of south India" conducted by P. Prabhu and her associates also revealed that the most common reason $(41.5 \%)$ for getting into drugs was peer influence or peer pressure (17).

Most of the abusers i.e. $65.52 \%$ were introduced to drugs in the age group 17-24 years and $34.48 \%$ in the age group 10-16 years while in the study "Age of substance use initiation among treatment admissions aged 18-30" by Substance Abuse and Mental Health Services Administration (SAMHSA) U.S.A. majority i.e. $38.6 \%$ were introduced to drugs when they were 11 or younger (17) which is understandable as the U.S. is a developed country with easier access to drugs.

It was found that most abusers were into drugs because it provided them with calmness and relaxation feeling $(25.86 \%)$ followed by euphoria (14.96\%). $8.7 \%$ of the total seem addicted.

According to our study a number of health effects were seen such as oral problems $(21.83 \%)$, respiratory problems $(14.94 \%)$, gastrointestinal troubles $(11.49 \%)$ and also nervous disorders $(3.44 \%)$. One of the most significant finding was loss of work efficacy $(17.4 \%) ; 13.37 \%$ of the people also reported absence from school and work. The study "Assessment of causes, prevalence and consequences of alcohol and drug abuse among Mekelle University, CSSL 2nd year students" conducted by Dept. of Psychiatry Mekelle University, Ethiopia revealed that $90 \%$ of the subjects had academic consequences, $75 \%$ had psychological consequences, $70 \%$ had health consequences, $80 \%$ had behavioral consequences of drug abuse (19). However the data isn't quite relatable as it is a study conducted in another country with different parameters.

The household factors for drug abuse was found to be financial crisis $(25.28 \%)$ followed by lack of guidance $(22.98 \%)$ and household violence $(18.96 \%)$. However the research by Journal of Pakistan Medical Association shows that family has little or no influence $(0.5 \%)$ in drug abuse, $8 \%$ were due to peer pressure, $6 \%$ were due to employment issues, $5 \%$ were related to problems with spouse.

$43.68 \%$ had positive family history of drug use as revealed by our study. The study by Sorab Gupta reveals $57.4 \%$ individuals with positive family history of drug use. Thus there seems to be a greater tendency of drug abuse in persons with positive family history.

$51.6 \%$ of the abusers revealed that their families were unaware of the fact, $22.6 \%$ revealed that their families were aware but indifferent, $15.6 \%$ had been sent to counselling by family and $10.46 \%$ were sent for rehabilitation. The study "Substance use and addiction research in India" by Pratima Murthy, N. Manjunatha and Vivek Benegal throws light upon the results obtained after a 5 year treatment and rehabilitation period of 800 drug addicts at a de addiction centre which is as follows:

3\% i.e. 504 persons did not use the services provided beyond 1 month

$81 \%$ of the remaining i.e. 240 persons of 296 were successful in maintaining abstinence.

- Upon further study it was found that the successful de addiction cases were constantly receiving support from family and friends (20)

$6.33 \%$ individuals have stopped drug intake while $93.67 \%$ continue to abuse drugs, $72.41 \%$ are aware of the ill effects of drugs. . However the study by Sorab Gupta reveals $100 \%$ of the abusers still are active into drugs, $97.3 \%$ are aware of the ill effects.

\section{Summary}

On the basis of our project on 'A study on Substance abuse among young people of age group 10-24 years" in the urban slums of Jorhat Assam' on 174 individuals, it was found that

$-87.99 \%$ Males and $12.21 \%$ Females were abusing one kind of substance or the other.

-Among the 174 respondents, $36.2 \%$ belongs to age group 2224 years, $33.9 \%$ of $19-21$ years, $20.7 \%$ belongs to $16-18$ years, $7.56 \%$ belongs to age group $13-15,0.58 \%$ belongs to age group 10-12 years.

-The substances abused were tobacco by $52.87 \%$ abusers, alcohol by $27.01 \%$ abusers, and marijuana by $4.60 \%$ abusers, Dendrite by $6.32 \%$ while $9.2 \%$ consume combination of two or more drugs.

-Substance abuse is done on a daily basis by $73.55 \%$ individuals and on weekly basis by $21.84 \%$ individuals and monthly basis by $4.61 \%$ individuals.

-The common sources of substanceabuse were nearby retailer in $64.36 \%$ individuals, drug handler in $5.17 \%$, friends in 
$6.32 \%$, family in $0.57 \%$ and $23.57 \%$ due to combination of two or more sources

-Out of 174 respondents, $34.48 \%$ individuals started substance abuse at the age of 10-16 years and $65.52 \%$ started substance abuse at the age of 17-24 years.

-Out of 174 respondents, substance abuse has produce effects like calm and relaxed feeling in $25.86 \%$, euphoria in $14.96 \%$, and hallucination in $7.47 \%$ and depression in $1.72 \%$ abusers.

-Out of 174 respondents, health effects were seen like oral problems in $21.83 \%$, respiratory problems in $14.94 \%$, and gastrointestinal problems in $11.49 \%$ and nervous disorders in $3.44 \%$ individuals.

-The common reasons for substance abuse was found to be peer pressure in $47.5 \%$, followed by experimentation in $18.96 \%$,stess in $8.04 \%$,personal loss in $5.17 \%$,depression in $9.19 \%$ and in $4.01 \%$ due to two or more of above reasons.

-The household factors responsible for substance abuse are found to be lower socio economic status in $25.28 \%$ abusers, lack of guidance in $22.98 \%$ and household violence in $18.96 \%$ individuals, negligence in $9.19 \%$ individuals.

-Out of 174 respondents, $43.68 \%$ has family history of substance abuse and $56.32 \%$ has no family history of substance abuse.

-Among the substance abusers, 51.6\% them revealed that their families were unaware of the fact, $22.6 \%$ revealed that their families were aware but indifferent, $15.6 \%$ were sent for counselling and $10.46 \%$ were sent for rehabilitation.

- Out of 174 respondents, $72.41 \%$ are aware of ill-effects of substance abuse while $27.59 \%$ are unaware of ill-effects.

\section{CONCLUSION}

As the problem of substance abuse is increasing worldwide, and has in the recent years become a global problem also affecting our country, we tried to find out the trends of substance abuse, i.e. their sources, contributing factors, household environments leading to substance abuse, etc. among 174 young people from Urban slums of Jorhat, Assam. Based on our study, we came to the following conclusions-

Majority of the respondents were males .Among the substance abusers, majority of them belonged to age group of 22-24 years, followed by the age group of 19-21 years. The major drug abused was found to be tobacco, followed by alcohol .For majority of people the source of obtaining drug is from nearby retailers. It was also found that most abusers were into drugs because it provided them with a calm and relaxed feeling followed by euphoria and addiction. A number of health effects were seen among the substance abusers with majority having oral problems and/or respiratory problems. Majority of the abusers were introduced to drugs at the age of 17-24 years that is in school going period. Also, study of the frequency of substance abuse revealed that majority of them take the drugs on a daily basis, while some consume it weekly or monthly. The most common reason for getting into substance abuse was found to be peer influence or peer pressure. It is followed by experimentation. The leading household factor contributing to drug abuse was found to be due to lower socioeconomic status followed by lack of guidance and household violence. A large number of the subjects were aware of the ill effects of substance abuse while the rest were unaware.

\section{Recommendations}

- Based on our study it was found out that many people were unware of the ill effects of substance abuse. Under such circumstances, the creating awareness primarily focussing on these unware groups, is utmost required as a viable solution.

- Making people aware of the hamper it does on one's day to day work, leading to a reduction in human efficiency and productivity could make them help in doing away with substance abuse.

- Advices was given to this group of people. There should be counselling calls for moral boosting and it should be explained not to abuse substance to escape problems.

- General advises on good health and adverse effects that substance abuse imparts on one's health should be done by organising health camps, mass gatherings etc.

- Seeking help from rehabilitation centres should be encouraged.

- The dangers of long term ill effects were explained.

Author Contributions: ANK: Concept, Data collection and/or processing, Analysis and/or interpretation, Literature review, writing of the article, revisions

Financial \& competing interest's disclosure: The authors have no relevant affiliations or financial involvement with any organisation or entity with a financial interest in or financial conflict with the subject matter or materials discussed in the manuscript. This includes employment, consultancies, honoraria, stock ownership or options, expert testimony, grants or patents received or pending, or royalties.

Conflict of interest: The author declared no potential conflicts of interest with respect to the research, authorship, and/or publication of this article. This research did not receive and specific grant from funding agencies in the public, commercial, or not-for-profit sectors.

Ethical approval: The study was conducted according to the guidelines of the Declaration of Helsinki and approved by Local Ethical Committee.

\section{REFERENCES}

1. World Health Organization. Guide to drug abuse: epidemiology. No WHO/MSD/MSB/00.3. World Health Organization, 2000.

2. Government of India. "National Youth Policy 2014." 2014

3. PARK'S, K., et al. Park's text book of preventive and social medicine. 2021.

4. DADWANI, Roma S.; THOMAS, Tintu. Prevalence of substance abuse: a community based study. International journal of community medicine and public health (Gujarat), 2016, 3.3: 647-650.

5. Drug abuse project, North Eastern Hill University; Problem of Drug Addiction in North east Regions

6. World Bank. World development report 2015: Governance and the law. The World Bank, 2015. 
7. Katoki, Kaushik, Srabana Misra Bhagabaty, and Manoj Kalita "Silhouette of substance abuse amongst an adolescent sample group from urban slums of Guwahati metro, North East India." International Journal of Medical Research \& Health Sciences 5.3 (2016): 1-8.

8. Goswami, Himakshi. "Substance abuse among youths at Guwahati City, Assam (India): Major Instigator and Socio-demographic Factors." Int Educ Res J 1 (2015): 39-42.

9. Ambwani SR, Kaur R. Impact of oral cannabis consumption on health: A cross-sectional study. Journal of Pharmacology and Pharmacotherapeutics. 2021 Apr 1;12(2):91.

10. Murthy P, Manjunatha N, Subodh BN, Chand PK, Benegal V Substance use and addiction research in India. Indian journal of psychiatry. 2010 Jan;52(Suppl1):S189.

11. Nadeem A, Rubeena B, Agarwal VK, Piyush K. Substance abuse in India. Pravara Med Rev. 2009;4(1):4-6.

12. Tsering D, Pal R, Dasgupta A. Substance use among adolescent high school students in India: A survey of knowledge, attitude, and opinion. Journal of Pharmacy and Bioallied Sciences. 2010 Apr;2(2):137.

13. K. Park; Health Information and Basic Medical Statistics: 23rd edition
14. Ghulam R, Verma K, Sharma P, Razdan M, Razdan RA. Drug abuse in slum population. Indian journal of psychiatry. 2016 Jan;58(1):83.

15. Gupta S, Sarpal SS, Kumar D, Kaur T, Arora S. Prevalence, pattern and familial effects of substance use among the male college students-a North Indian study. Journal of clinical and diagnostic research: JCDR. 2013 Aug;7(8):1632.

16. Prabhu P, Srinivas R, Vishwanathan K, Raavi A. Factors influencing alcohol and tobacco addiction among patients attending a de-addiction Centre, South India. Journal of International Society of Preventive \& Community Dentistry. 2014 May;4(2):103.

17. Abuse S. Mental Health Services Administration. Results from the 2013 Jan 10;2:013.

18. Tulu SK, Keskis W. Assessment of causes, prevalence and consequences of alcohol and drug abuse among Mekelle university, CSSL 2nd year students. American Journal of Applied Psychology. 2015;3(3):47-56.

19. Murthy P, Manjunatha N, Subodh BN, Chand PK, Benegal V. Substance use and addiction research in India. Indian journal of psychiatry. 2010 Jan;52(Suppl1):S189. 